\title{
Comparison of HIV/AIDS Rates Between U.S.-Born Blacks and African- Born Blacks in Utah, 2000 - 2009
}

\author{
Crystal Ashton ${ }^{1}$, Scott A. Bernhardt ${ }^{*}, 2$, Mike Lowe ${ }^{3}$, Matthew Mietchen ${ }^{4}$ and Jim Johnston ${ }^{1}$ \\ ${ }^{I}$ Department of Health Promotion and Education, University of Utah, Salt Lake City, Utah, USA \\ ${ }^{2}$ Department of Biology, Utah State University, Logan, Utah, USA \\ ${ }^{3}$ Department of Family and Preventive Medicine, University of Utah, Salt Lake City, Utah, USA \\ ${ }^{4}$ Utah Department of Health, Salt Lake City, Utah, USA
}

\begin{abstract}
The Utah Department of Health currently groups African-born blacks with U.S.-born blacks when reporting HIV/AIDS surveillance data. Studies suggest that categorizing HIV/AIDS cases in this manner may mask important epidemiological trends, and the distinct differences between these two populations warrant disaggregating data prior to reporting. The purpose of this study was to characterize the HIV/AIDS positive populations in U.S. and African-born blacks in Utah and evaluate the need for disaggregating the two groups. A total of 1,111 cases were identified through the statewide electronic HIV/AIDS Reporting System from 2000 - 2009. Data were analyzed for prevalence of HIV diagnosis for African-born blacks, U.S.-born blacks, and U.S.-born whites. Secondary analysis included HIV diagnosis by age, sex, African region of nativity, transmission risk factors, and differences in late diagnosis of HIV infection. U.S.-born whites accounted for $914(82.3 \%)$ cases, and had the lowest annual prevalence (4/100,000). Conversely, African-born and U.S.born blacks had the highest prevalence, $162 / 100,000$ and 24/100,000 respectively. African-born blacks made up $0.25 \%$ of the total population, but accounted for $7.9 \%$ of all HIV/AIDS cases. African-born black males were more likely to report "no reported risk" for HIV transmission than U.S.-born black males. Of African-born blacks, 55.7\% reported East-African nativity. These results demonstrate the importance of stratifying the black/African American racial category by Africanborn and U.S.-born blacks when collecting and reporting HIV/AIDS state surveillance data even in a low-incidence state, which will better inform prevention and linkage-to-care efforts in Utah.
\end{abstract}

Keywords: HIV, AIDS, surveillance, Utah, epidemiology, African-born.

\section{INTRODUCTION}

The black/African American population has been significantly impacted by human immunodeficiency virus (HIV) from the beginning of the epidemic to the present day. Based on data collected from the National HIV Surveillance System from 2005 - 2008, blacks/African Americans represented $43.6 \%$ of the population yet accounted for $50.3 \%$ of new HIV infections in 37 states with name-based, confidential HIV reporting [1]. Adding to the disproportionate burden of infection, blacks/African Americans' survival following diagnosis is lower than any other race/ethnicity in the U.S. with the exception of American Indian/Alaska Natives [2]. Africanborn blacks represent a growing and increasingly important subgroup of the black/African American population. Studies show that African-born black immigrants are more likely than U.S.born blacks to be infected with HIV [3-5]. Among black/African American HIV diagnoses from 2003-2004 in eight U.S. metropolitan areas, up to $50 \%$ of cases occurred in African-born individuals [3].

Past studies point to significant epidemiological and cultural differences between African-born and U.S-born blacks regarding HIV [6-8]. African-born blacks are more

*Address correspondence to this author at the Department of Biology, Utah State University, Logan, Utah, USA; Tel: (435) 797-3721;

E-mail: scott.bernhardt@usu.edu likely to be infected with different strains of HIV, have different cultural values concerning health and sexuality, and have lower levels of knowledge about HIV transmission and treatment availability than U.S.-born blacks [6-8]. Due to the important differences between U.S.-born and African-born blacks, some states with moderate-to-high HIV incidence and large African immigrant populations have recognized the need to distinguish between these groups when conducting epidemiological surveillance. Increasingly, states that distinguish cases based on country of birth are finding higher rates of infection among foreign-born individuals. Surveillance in Minnesota from 2002-2005 showed that African-born individuals represented approximately $20 \%$ of HIV cases in the state, but made up less than $1 \%$ of the population [9]. The highest number of HIV diagnoses in Massachusetts from 2002-2004 were among African-born persons, comprising $38 \%$ of new cases $[10,11]$.

As of 2009, there were approximately 6,600 African-born individuals living in Utah, making up approximately $0.25 \%$ of the population $[12,13]$. Utah uses the standard CDC race classification to categorize HIV cases, including American Indian/Alaska Native, Asian, Black/African American, Native Hawaiian/Pacific Islander, White, Latino, and Multirace. Historically, Utah's HIV/AIDS Surveillance reports have not included analysis by country of birth. However, the 2009 Utah HIV/AIDS Surveillance Report Profile included country of birth for the first time and reported a $33 \%$ 
increase in HIV diagnoses in African-born persons from 2008-2009 [14]. The purpose of this study was to expand on these findings by further disaggregating HIV/AIDS surveillance data and to evaluate the prevalence of HIV/AIDS in Utah based on country of birth for both U.S. and African-born blacks. In addition, this study sought to identify differences in transmission risk factors between U.S. and African-born blacks, as well as understanding late diagnosis among these populations.

\section{METHODS}

We analyzed data reported to the Utah Department of Health (UDOH) for individuals diagnosed with HIV infection (with or without AIDS) from 2000 to 2009. Confidential HIV surveillance data is collected from various sources in Utah, including reported HIV infections from private medical providers, public and private laboratories, and state and local HIV prevention programs. The information collected is entered into the National Electronic HIV/AIDS Reporting System (eHARS), for data analysis. Utah cases are defined as individuals newly diagnosed with HIV and living in Utah. All individuals reported to be living in Utah with HIV are entered into eHARS regardless of where they were diagnosed; however, those individuals with a previous diagnosis of HIV in another state were excluded in the dataset for this analysis and were not counted as Utah cases. Foreign-born individuals living in Utah at the time of diagnosis are counted as Utah cases, although infection may have occurred in their country of origin. The data collection tool for eHARS is the standard HIV/AIDS case report generated by the CDC. A limited data set was extracted from eHARS in collaboration with the UDOH. All personal identifiers were removed prior to receiving the data set. The data set contained information such as country of birth, laboratory and clinical findings, pregnancy status, and possible modes of HIV exposure.

\section{Study Sample}

We examined reported HIV infections (with or without AIDS) among individuals diagnosed in Utah from 2000 to 2009. Race was collected and reported in the eHARS database where it was separated into categories for the analysis. The primary focus of this analysis was to understand HIV rates and potential differences that may exist between foreign-born and U.S.-born blacks. The racial category "Black" was initially divided into four groups: 1) native-born U.S., 2) African-born, 3) other foreign-born, or 4) missing country of birth. All foreign-born blacks in Utah were from the African continent with the exception of nine cases reported as other foreign-born. These nine cases were excluded from this analysis because they represented seven different countries of origin, and immigrant population estimates in Utah from these countries were unavailable for comparison in the analysis. Foreign-born whites, Latinos, Native Americans, Pacific Islanders, Asians, and cases with missing data were also excluded from the analysis. U.S. born whites were included as a reference group because they account for the largest number of new HIV infections in Utah. A total of 1,111 Utah cases were included for analysis. Sex was identified and included in the analysis to ultimately generate six race, country of nativity and sex categories ("U.S.-Born White - Male/Female (M/F)", "U.S.-Born
Black - M/F", and African-born Black - M/F"). Eight cases that were provided in the data set were removed from analysis due to missing and/or incomplete information (i.e. missing country of birth).

To perform various calculations, such as prevalence of HIV/AIDS for U.S. and African-born blacks in Utah, estimates of the total population for different classifications were required. The CDC uses post-census bridged-race annual population estimates by year, state, and county for 1990-2009. These data have population estimates by age, sex, and race. Annual bridged-race population estimates for Utah were obtained using CDC post-census data for the years 2000-2009 [12]. These were aggregated across age and county to obtain an annual state estimate by year and racial characteristics.

While the population estimates include information on race, these data do not include population estimates by country of birth as well. Country of birth is critical to the analysis, since without this information it is not possible to distinguish a "black" HIV case as U.S.- or African-born. HIV surveillance collects country of origin data for each individual. An ideal scenario would be to generate population weights by nationality. This breakdown at the country of origin level was not possible to obtain because the data specific to Utah do not appear to exist. Annual population estimates for African-born individuals in Utah were obtained from Migration Policy Institute [5]. With these estimates, data analysis was performed at the following level: U.S.-born, African-born, or Other foreign-born (any country of birth other than the United States or on the African continent).

\section{Data Analysis}

We conducted five sets of analyses for HIV-infected individuals in Utah. The initial analyses were conducted on all HIV-infected cases. As the study developed, our attention was primarily focused on HIV-infected native-born and African-born black people. First, we examined prevalence of HIV diagnoses in Utah from $2000-2009$. The prevalence was then examined at the level of sex, race and whether they were U.S. or African-born. These cases were further evaluated by calculating annual prevalence rates per 100,000 based on yearly population estimates. Second, we calculated HIV diagnosis estimates by age classification for native and African-born black people for all ten years of the study combined. Age grouping classifications have been determined by CDC and were used in this analysis. The statistical test used for the normally distributed variables was the Z-test for two proportions and reported as a $p$ value. All statistical analyses were performed, using a $95 \%$ confidence interval, with SAS version 9.1 (Statistical Analysis Software). Third, African-born HIV infected individuals for all ten years of the study combined were estimated by African region of nativity. For the geographic classification and analysis, we relied upon the United Nations regional sub-grouping definitions for Africa and included those countries as defined [15]. Fourth, HIV diagnoses was examined according to transmission risk factors and determined for the native and African-born black classification. The CDC's categories for HIV surveillance include male-to-male sexual contact (MSM), injection drug 
use (IDU), combined MSM contact and IDU, high-risk heterosexual contact, no reported risk (NRR) and other. Heterosexual transmission is assigned to individuals who have sex with a partner who is HIV positive, a MSM, and/or an IDU. No reported risk (NRR) is counted when there is heterosexual exposure but the sexual partner is not reported as being HIV positive, a MSM, and/or an IDU. The "other" category includes perinatal exposure, hemophilia, and blood transfusions. Finally, we examined differences in late diagnoses of HIV infection and progression to AIDS among native vs African-born black people for all ten years of the study combined.

\section{RESULTS}

\section{Demographics}

From 1983 through the end of December 2009, there were 2,467 people living in Utah who were diagnosed with HIV/AIDS. During the 2000-2009 study period, 1,516 cases of HIV were reported. Of this number, six cases categorized as black/African American were excluded because they did not have complete country-of-birth information. Individuals that identified as a race category other than black and white were also excluded from the analysis, leaving 1,111 that met our study criteria (Fig. 1). Of the total number of HIV diagnoses reported in our study sample, $914(82.27 \%)$ were among U.S.-born whites and $64(5.76 \%)$ were among U.S.born blacks (Table 1). Of the foreign-born, 88 (7.92\%) were African-born blacks and 47 (4.23\%) cases were foreign-born white. In this analysis, African-born blacks represent $57.89 \%$ of all black HIV diagnoses. During this ten year study period, U.S.-born blacks living in Utah made up $1.28 \%$ of the total population and represented $5.76 \%$ of HIV diagnoses whereas, African-born blacks represented $0.25 \%$ of the total Utah population and $7.92 \%$ of all HIV/AIDS diagnoses in Utah.
Table 1. HIV Diagnosis and Prevalence by Sex Among African-Born, U.S.-Born White and Blacks in Utah $2000-2009$

\begin{tabular}{|c|c|c|c|}
\hline $\begin{array}{c}\text { Individual } \\
\text { Classification }\end{array}$ & $\begin{array}{l}\text { Number in } \\
\text { Sample (n) }\end{array}$ & Percent & $\begin{array}{c}\text { HIV } \\
\text { Prevalence }\end{array}$ \\
\hline African-born & 88 & 7.92 & $162 / 100,000$ \\
\hline U.S.-born blacks & 64 & 5.76 & $24 / 100,000$ \\
\hline U.S. white & 914 & 82.26 & $4 / 100,000$ \\
\hline $\begin{array}{c}\text { Individual } \\
\text { Classification }\end{array}$ & $\begin{array}{l}\text { Number in } \\
\text { Sample (n) }\end{array}$ & Percent & $\begin{array}{c}\text { HIV } \\
\text { Prevalence }\end{array}$ \\
\hline African-born black female & 54 & 4.86 & $210 / 100,000$ \\
\hline African-born black male & 34 & 3.06 & $146 / 100,000$ \\
\hline U.S.-born black female & 11 & 0.99 & $9 / 100,000$ \\
\hline U.S.-born black male & 53 & 4.77 & $40 / 100,000$ \\
\hline U.S.-born white female & 99 & 8.91 & $1 / 100,000$ \\
\hline U.S.-born white male & 815 & 73.36 & $8 / 100,000$ \\
\hline
\end{tabular}

\section{HIV Diagnosis and Prevalence}

From 2000 to 2009, U.S.-born male and female whites accounted for $60.29 \%$ of Utah's HIV cases. Even with this high proportion of HIV cases, the HIV prevalence among U.S.-born whites was among the lowest rate (4 per 100,000) of all of the comparison groups. Comparisons of prevalence of HIV diagnoses in Utah were divided into African-born blacks, U.S.-born blacks, and U.S.-born white classifications (Tables 1 and 2). African-born blacks have a higher HIV diagnosis prevalence (162 per 100,000) when compared to U.S.-born blacks. (24 per 100,000). As indicated in Table 1,

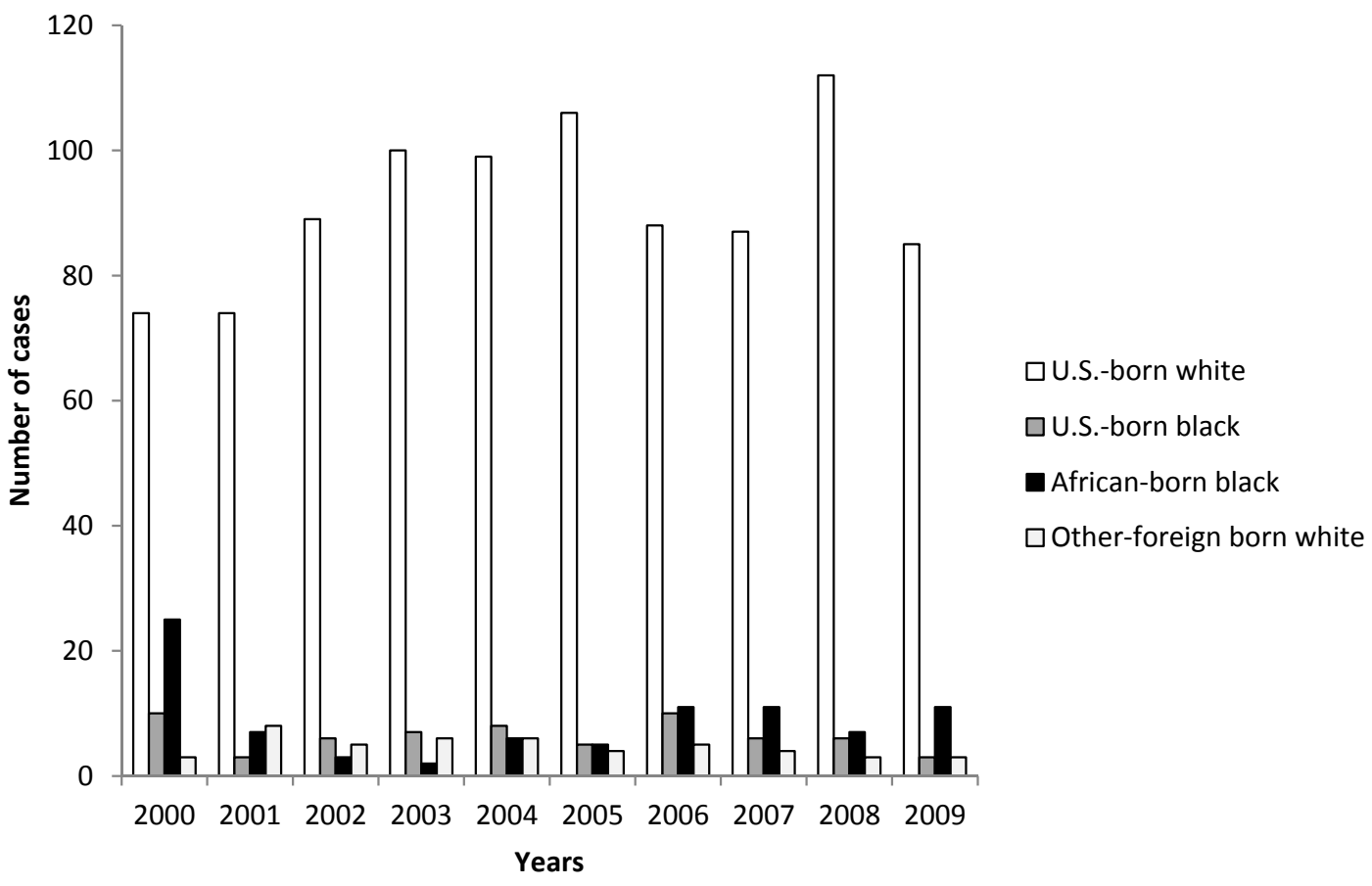

Fig. (1). HIV diagnoses by U.S.-born white, U.S.-born black, African-born blacks, and other foreign born white in Utah $2000-2009$ 
the HIV prevalence for African-born females (210 per $100,000)$ is more than twenty times that of U.S.-born black females (9 per 100,000; $p<0.05$ ) and more than two hundred times than that of white U.S.-born females (1 per $100,000)$ living in Utah. Diagnosis rates among African-born females are 1.44 times greater than African-born males and 5.25 times higher than U.S.-born black males. African-born males are over three times more likely to be infected than U.S.-born black males $(p<0.05)$.

\section{Age Correlation and African Region of Nativity}

Using CDC's age classification, the largest cumulative proportion of HIV diagnoses for years 2000 to 2009, for both U.S.-born and African-born blacks, was within the 30 to 39 age group (Table 2). In this age category, there were 20 (31.25\%) U.S.-born black individuals and 36 (40.91\%) African-born black individuals with HIV living in Utah. There was a significantly larger proportional difference of diagnoses for U.S.-born blacks ages from 40 to $49(\mathrm{n}=19$, $29.69 \%$ ) compared to African-born blacks $(n=10,11.36 \%)$. There were very few cases in Utah in the younger age groups, from ages 1 to 19 , for both U.S.-born and African- born blacks (12 total cases). The youngest age group that did account for a substantial case load was between years 20 to 29, where African-born blacks had 28 cases (31.82\%) and U.S.-born blacks had 18 cases $(18.28 \%)$.

HIV diagnoses among African-born blacks in Utah during the study period represented eighteen different countries and an even greater number of cultures and languages. Among African-born blacks, 55.68\% came from East Africa, $17.05 \%$ from West Africa, $15.9 \%$ from Middle Africa, 11.36\% from Southern Africa. Even within the U.N. African regional classifications, there was not an even distribution of cases by country. For example, of the 49 individuals that were categorized as East Africa, close to half of those cases were among Ethiopians, followed by Kenyan and Burundian cases (Table 3).

\section{HIV Transmission}

Risk categories that are most significant by sex were calculated for both U.S.-born and African-born blacks (Table 4). Overall, we found a substantial number of cases in the high risk categories of MSM $(n=25)$, and MSM/IDU $(n=8)$ in

Table 2. Estimates of HIV Diagnosis Among Blacks Born in Africa and the U.S. Distributed by Male/Female and Age Category

\begin{tabular}{|c|c|c|c|c|c|c|c|c|c|c|}
\hline \multirow[b]{2}{*}{ Gender } & \multicolumn{4}{|c|}{ U.S.-Born Blacks } & \multicolumn{4}{|c|}{ African-Born Blacks } & \multirow{2}{*}{ z Test } & \multirow{2}{*}{$p$ Value } \\
\hline & $\mathbf{n}$ & $\mathbf{N}$ & Percent & C.I. in \%* & $\mathbf{n}$ & $\mathbf{N}$ & Percent & C.I. in \%* & & \\
\hline Male & 53 & 19735 & 0.27 & $0.2,0.34$ & 34 & 3446 & 0.99 & $0.66,1.32$ & 6.23 & $<.05$ \\
\hline Female & 11 & 16516 & 0.07 & $0.03,0.11$ & 54 & 3181 & 1.7 & $1.25,2.15$ & 14.5 & $<.05$ \\
\hline Total & 64 & & & & 88 & & & & & \\
\hline Age at Diagnoses & $\mathbf{n}$ & & Percent & C.I. in \%* & $\mathbf{n}$ & & Percent & C.I. in \%* & & \\
\hline $0-12$ & 1 & & 1.56 & $0,4.60$ & 7 & & 7.95 & $2.30,13.6$ & & \\
\hline $13-19$ & 1 & & 1.56 & $0,4.60$ & 3 & & 3.41 & $0,7.20$ & & \\
\hline $20-29$ & 18 & & 28.13 & $17.11,39.15$ & 28 & & 31.82 & $22.09,41.55$ & & \\
\hline $30-39$ & 20 & & 31.25 & $19.89,42.61$ & 36 & & 40.91 & $30.64,51.18$ & & \\
\hline $40-49$ & 19 & & 29.69 & $18.50,40.88$ & 10 & & 11.36 & $4.73,17.99$ & & \\
\hline $50-59$ & 5 & & 7.81 & $1.24,14.23$ & 3 & & 3.41 & $0,7.20$ & & \\
\hline $60+$ & 0 & & 0 & 0 & 1 & & 1.14 & $0,2.36$ & & \\
\hline
\end{tabular}

Table 3. Utah HIV Cases in African-Born Individuals by African Region of Nativity

\begin{tabular}{|l|c|c|}
\hline United Nations Regional Sub-Grouping for Africa & $\begin{array}{c}\text { No. of African-Born HIV Cases } \\
\text { in Utah by Region of Nativity }\end{array}$ & $\begin{array}{c}\text { Percent of African-Born HIV Cases } \\
\text { in Utah by Region of Nativity }\end{array}$ \\
\hline \hline $\begin{array}{l}\text { East Africa } \\
\text { Ethiopia, Burundi, Kenya, Malawi, } \\
\text { Rwanda, Somalia, Tanzania }\end{array}$ & 49 & 55.68 \\
\hline $\begin{array}{l}\text { West Africa } \\
\text { Ghana, Liberia, Mali, Togo }\end{array}$ & & \\
\hline $\begin{array}{l}\text { Middle Africa } \\
\text { Angola, Cameron, Congo }\end{array}$ & 15 & 17.05 \\
\hline $\begin{array}{l}\text { Southern Africa } \\
\text { Botswana, Namibia, South Africa }\end{array}$ & 14 & \\
\hline
\end{tabular}


U.S.-born black males. Over $60 \%$ of HIV infected U.S.-born black males reported MSM or MSM/IDU, compared to African-born black males who accounted for $8.82 \%(\mathrm{n}=3)$ for MSM. There were no transmissions of IDU for Africanborn black males; however, the percentage of U.S.-born black males IDU was $11.32 \%$. We also saw in males a higher proportion of cases attributed to high-risk heterosexual activity for African-born $(20.59 \%)$ than what was reported for U.S.-born black males (5.66\%).

An interesting finding was the difference in cases attributed to "no reported risk" (NRR). This analysis revealed that $59.09 \%(\mathrm{n}=52)$ of HIV positive African-born men and women were NRR, while $21.88 \%(\mathrm{n}=14)$ of U.S.born blacks were NRR, as indicated by combining sex in Table 4 (totals not shown). A closer look demonstrates that African-born men were almost three times more likely to have no reported risk than U.S.-born black men $(64.71 \% v s$ $18.87 \%)$.

When country of birth is factored in for analysis of the female data, the reporting of the NRR transmission risk characteristic follows a similar, but less pronounced, discrepancy in reporting as seen in the male data. For African-born females, NRR accounted for $55.56 \%(\mathrm{n}=30)$ as compared to $36.36 \%(n=4)$ in U.S.-born black females. Finally, heterosexual transmission statistics were similar in both African-born and U.S.-born blacks.

\section{Concurrent AIDS and Late Diagnoses of HIV Infection}

New cases with a concurrent HIV and AIDS diagnoses and late testers (cases that progress to AIDS within twelve months from first positive test) were combined and examined. U.S. born blacks, male and female, had the highest proportion of concurrent HIV and AIDS diagnoses and late testers $(65.63 \%)$, followed by African-born blacks $(52.27 \%)$ and U.S. born whites $(45.73 \%)$ (Table 5). As the data is studied by sex, U.S.-born black males have a higher percentage of cases that were diagnosed concurrently with AIDS than African-born men $(77.36 \%$ vs 55.88\%). However, $50.0 \%$ of African-born women were concurrently diagnosed with AIDS compared to $9.09 \%$ of U.S.-born black women. We were unable to analyze concurrent diagnosis of AIDS and progression to AIDS within twelve months data for different age and transmission categories due to the overall small HIV case load in the state of Utah.

\section{DISCUSSION}

Findings from this study suggest that current HIV/AIDS analysis and reporting practices in Utah do not fully capture the changing demographics and epidemiological trends within the state. Of significance is the finding that HIV prevalence is over six times higher among African-born blacks than U.S.-born blacks. And while U.S.-born whites continue to account for over eighty percent of new HIV cases in the state, emerging trends in the black minority population warrant closer attention. The current practice of grouping all blacks together under the category blacks/African-American fails to take into consideration that many black people living in Utah emigrated from African regions with elevated HIV prevalence and significantly different transmission patterns. This study found a high percentage of African-born males (64.7\%) and females $(55.6 \%)$ who were classified as NRR. The high number of African-born cases $(\mathrm{n}=28)$ in the year 2000 is likely explained by changes in immigration rules that year which established a formal program for the resettlement of HIV positive refugees in the U.S. Utah was one of the first six resettlement states selected under these new rules.

This study found a high percentage of African-born males $(64.7 \%)$ and females $(55.6 \%)$ who were classified as NRR. The CDC-defined NRR transmission category includes individuals for whom no mode of exposure has been identified and for individuals with heterosexual exposure if the partner is not at high-risk for HIV. The CDC

Table 4. Estimates of HIV Diagnosis Among Blacks Born in Africa and the U.S. Distributed by Male/Female and Transmission Category

\begin{tabular}{|l|c|c|c|c|c|c|}
\hline \multicolumn{1}{|c|}{ Transmission Category By Gender } & \multicolumn{3}{|c|}{ U.S.-Born Blacks } & \multicolumn{3}{c|}{ African-Born Blacks } \\
\hline \multicolumn{1}{|c|}{ Male } & N=53 & Percent & C.I. in \% & N=34 & Percent & C.I. in \% \\
\hline \hline Male-to-male sexual contact & 25 & 47.17 & $33.73,60.50$ & 3 & $0,18.35$ \\
\hline Injection drug use & 6 & 11.32 & $2.79,19.85$ & 0 & 0.00 & 0 \\
\hline MSM \& IDU & 8 & 15.09 & $5.45,24.73$ & 0 & 0.00 & 0 \\
\hline Heterosexual contact & 3 & 5.66 & $0,11.88$ & 7 & 20.59 & $7.00,34.18$ \\
\hline No reported risk & 10 & 18.87 & $8.34,29.40$ & 22 & 64.71 & $48.65,80.77$ \\
\hline Other* & 1 & 1.87 & $0,5.54$ & 2 & 5.88 & $0,13.79$ \\
\hline & N=11 & Percent & C.I. in \% & N=54 & Percent & C.I. in \% \\
\hline \hline Injection drug use & 3 & 27.27 & $0.95,53.59$ & 1 & 1.85 & $0,5.44$ \\
\hline Heterosexual contact & 4 & 36.36 & $7.93,64.79$ & 19 & 35.19 & $22.45,47.93$ \\
\hline No reported risk** & 4 & 36.36 & $7.93,64.79$ & 30 & 55.56 & $42.31,68.81$ \\
\hline Other* & 0 & 0.00 & 0 & 4 & 7.41 & $0.42,14.40$ \\
\hline
\end{tabular}

*Other includes perinatal exposure, blood transfusion; C.I. $=95 \%$ Confidence interval.

**Includes one adopted child with unknown birth history (surveillance program unable to verify as perinatal exposure). 
Table 5. Concurrent HIV/AIDS Diagnoses and Late Testers

\begin{tabular}{|c|c|c|c|}
\hline $\begin{array}{c}\text { Place of Nativity, Race, } \\
\text { and Gender }\end{array}$ & HIV Positive & $\begin{array}{c}\text { \# of Individuals with a Concurrent AIDS } \\
\text { Diagnosis or Progressed to AIDS within 12 } \\
\text { Months of Diagnosis }\end{array}$ & $\begin{array}{c}\text { \% of Individuals with a Concurrent AIDS } \\
\text { Diagnosis or Progressed to AIDS within 12 } \\
\text { Months of Diagnosis }\end{array}$ \\
\hline \hline African-born Black F & 54 & 27 & 50.00 \\
\hline African-born Black M & 34 & 19 & 55.88 \\
\hline U.S.-born Black F & 11 & 1 & 9.09 \\
\hline U.S.-born Black M & 53 & 41 & 77.36 \\
\hline U.S.-born White F & 99 & 38 & 38.38 \\
\hline U.S.-born White M & 815 & 380 & 46.63 \\
\hline
\end{tabular}

currently defines high risk heterosexual exposure as heterosexual contact with a partner who is HIV-infected, a man who has sex with men, injection-drug users, or recipient of clotting factor for hemophilia or other coagulation disorders [16]. Our findings mirror those of at least one other study where African-born individuals were classified as NRR almost $70 \%$ of the time [3]. The high percentage of NRR cases among African-born persons is likely explained by heterosexual exposure, especially cases among women where no other risk factors are identified. While Utah has low HIV prevalence among women, and while the majority of HIV transmission is MSM, considering a 'Presumed Heterosexual' exposure category may help clarify transmission risk factors among both native and immigrant populations. This approach has been adopted by a growing number of cities and states, including New York City, New Jersey, Michigan and Virginia. In addition, Utah should consider the feasibility of interviewing foreign-born HIV positive individuals to clarify transmission risk factors.

Recent findings suggest that within the black community in the U.S. there is an increasing proportion of HIV infections that are transmitted through heterosexual contact. CDC data show that $68 \%$ of black females and $70.7 \%$ of black males reported HIV infection through heterosexual contact compared to $15.2 \%$ of white females and $11.0 \%$ of white males [1]. What is unclear is the extent to which differences in transmission patterns among African-born blacks in the U.S. skew epidemiological trends when data for U.S.-born and African-born blacks are grouped together. The findings from this study reinforce the need for a data collection tool that takes into account the growing cultural and ethnic diversity within the U.S. More precise reporting will likewise help policy makers allocate culturally relevant HIV prevention and care services that more accurately reflect needs within the community. The need for state health departments to disaggregate data is one of the priorities of the National African HIV/AIDS Initiative (NAHI) from the Office of Minority Health Resource Center (OMHRC) [17]. As the demographics of Utah are changing, factors such as race, ethnicity, and language are becoming increasingly important data points to monitor as they reveal risks for health care disparities in native-born as well as foreign-born populations.

The CDC defines 'late testers' as individuals who are diagnosed with AIDS within 12 months following their initial HIV diagnoses [18]. In this study, over half of African-born blacks (52.27\%) progressed to AIDS within the first 12 months following HIV diagnosis, in contrast to $65.63 \%$ of U.S.-born blacks. Our findings compare with trends seen in larger HIV studies, in which black/African Americans typically do not seek early testing. That both U.S.-born and African-born blacks had higher rates of late testing than whites may be partially explained by blacks having less knowledge about the availability of HIV treatment, limited access to health care, and socioeconomic factors related to poverty, all of which have been identified as barriers to early testing $[19,20]$. However, the high proportion of late testers in all groups evaluated in this study is a reminder that the progression of HIV infection to AIDS often occurs subtly, and demonstrates the importance of targeted HIV testing to high-risk groups. HIV prevention education should be tailored specifically to affected populations to account for cultural and demographic differences.

This study was subject to several limitations. First, Utah has a low annual prevalence of HIV infection among blacks/African Americans, which necessitated the need to use 10 years of HIV data to obtain sufficient sample sizes for the analysis. Second, because of the low number of HIV cases in Utah, analysis by sex and transmission category resulted in large confidence intervals. A third limitation was there was substantial missing data for specific variables of interest. For example, we were unable to evaluate CD4 counts and pregnancy status at time of HIV diagnosis due to missing data. Fourth, HIV waiver status for refugees was only available in eHARS for five years of the study (20052009). Knowing HIV waiver status is important because a refugee with a waiver automatically classifies the case as being infected prior to coming to the United States.

The study findings identify African-born blacks as an emerging population for targeted HIV prevention and care efforts that reflect the cultural and linguistic diversity of the African communities in Utah. Previously, black/African Americans had not been identified as a priority population, despite being highlighted in Utah HIV epidemiological reports for having disproportionate rates of infection. Findings reveal the importance of improved reporting of transmission risk factors among African-born blacks. Data collection tools need to be evaluated and revised to accurately measure demographic and transmission risk factors across an increasingly diverse population in Utah. Understanding HIV prevalence and risk factors in different Utah subpopulations will allow for a balanced and targeted 
approach to prevention, improved education to promote early testing, and appropriate distribution of treatment resources.

\section{ACKNOWLEDGMENTS}

The authors would like to thank the Utah Department of Health for the eHARS data set and to Dr. Ted Tatos, for his expertise in creating the population weights and annual estimates that were critical to the analysis. We also thank Karyn Leniek, MD, MPH, Utah Deputy State Epidemiologist, for reviewing and editing the manuscript.

\section{CONFLICT OF INTEREST}

The authors confirm that this article content has no conflict of interest.

\section{ABBREVIATIONS}

$$
\begin{array}{ll}
\text { AIDS } & =\text { Acquired Immunodeficiency Syndrome } \\
\text { CD4 } & =\text { Cluster of Differentiation } 4 \\
\text { CDC } & =\text { Centers for Disease Control and Prevention } \\
\text { eHARS } & =\text { Electronic HIV/AIDS Reporting System } \\
\text { HIV } & =\text { Human Immunodeficiency Virus } \\
\text { IDU } & =\text { Injection Drug Use } \\
\text { MSM } & =\text { Male-to-male sexual contact } \\
\text { NRR } & =\text { No Reported Risk } \\
\text { UDOH } & =\text { Utah Department of Health } \\
\text { U.S. } & =\text { United States of America }
\end{array}
$$

\section{REFERENCES}

[1] Center for Disease Control and Prevention (CDC). Disparities in Diagnoses of HIV Infection Between Blacks/African Americans and Other Racial/Ethnic Populations -37 states, 2005-2008. MMWR Mortal Wkly Rep 2011; 60: 93-8.

[2] Centers for Disease Control and Prevention. Diagnoses of HIV infection and AIDS in the United States and dependent areas, 2009. U.S. Department of Health and Human Services, Centers for Disease Control and Prevention, HIV Surveillance Report, Volume 21, 2011. Available at: http://www.cdc.gov/hiv/surveillance/resour ces/reports/20 09report/index.htm\#2 [Accessed August 25, 2011].

[3] Kerani RP, Kent JB, Sides T, et al. HIV among African-born persons in the United States: a hidden epidemic? J Acquir Immune Defic Syndr 2008; 49: 102-6.
[4] Kent JB. Impact of foreign-born persons on HIV diagnosis rates among blacks in King County, Washington. AIDS Educ Prev 2005; 17(6 Suppl B): 60-7.

[5] Johnson A, Hu Xiaohong, Dean HD. Epidemiologic differences between native-born and foreign-born black people diagnosed with HIV infection in 33 U.S. states, 2001-2007. Public Health Rep 2010; 125(Suppl 4): 61-9.

[6] Akinsete O, Sides T, Hirigoyen D, et al. Demographic, clinical, and virologic characteristics of African-born persons with HIV/AIDS in a Minnesota hospital. AIDS Patient Care STD 2007; 21(Suppl 5): $356-65$.

[7] Rosenthal L, Scott D, Kelleta Z, et al. Assessing the HIV/AIDS health services needs of African Immigrants to Houston. AIDS Edu Prev 2003; 15: 570-80.

[8] Halperin DT, Epstein H. Concurrent sexual partnerships help to explain Africa's high HIV prevalence: Implications for prevention. Lancet 2004; 364: 4-6.

[9] Sides T. Public Health Context of the Human Immunodeficiency Virus (HIV) Epidemic Among African-born Persons in Minnesota. University of Minnesota 2006; pg. 2.

[10] Massachusetts People Born Outside the U.S. HIV Fact Sheet. 2009. Available from: URL: http://www.mass.gov/Eeohhs2/doc/dph/aids $/ 2009$ profile/born_outside_us.pdf [Accessed March 5 2011].

[11] Massachusetts People Born Outside the U.S. HIV Fact Sheet. 2006. Available from URL: http://www.mass.gov/Eeohhs2/doc/pdh/aids/ 2006_profiles/non_us.pdf [Accessed March 5 2011].

[12] CDC Bridged-Race Population Estimates for the Year of 1990 2009. Available from URL: http://www.cdc.gov/nchs/nvss/bridge d race.htm

[13] Migration Policy Institute. MPI Data Hub. Available from URL: http://www.migrationinformation.org/datahub/state.cfm?ID=UT [Accessed February 22 2011].

[14] The Utah Department of Health, Bureau of Communicable Disease Report. 2009 HIV/AIDS Year-end Surveillance Report and 2009 Epidemiological Profile. Available from URL: http://health.utah.g ov/cde/sp.htm.

[15] United Nations. Composition of macro geographical (continental) regions, geographical sub-regions, and selected economic and other groupings. Available from URL: http://unstats.un.org/unsd/metho ds/m49/m49regin.htm\#africa [Accessed February 20, 2011].

[16] The Centers for Disease Control and Prevention (CDC). Current trends: heterosexually acquired AIDS - United States, 1993. MMWR 1994; 43: 155-60.

[17] The Office of Minority Health. The National African HIV/AIDS Initiative (NAHI). Available at: http://minorityhealth. hhs.gov/ templates/browse. aspx? $1 v l=2 \& l v l i d=183$ [Accessed July 27, 2011]

[18] Center for Disease Control and Prevention (CDC). Late Versus Early Testing of HIV - 16 Sites, United States, 2000-2003. MMWR 2003; 52: 581-6.

[19] Ebrahim SH, Andresson JE, Weilde P, Purcell DW. Race/ethnic disparities in HIV testing and treatment for HIV/AIDS: United States. 2001 AIDS Patient Care STDS 2004; 18: 27-30.

[20] Adimora AA, Schoenback VJ, Martinson FEA, et al. Heterosexually transmitted HIV infection among African Americans in North Carolina. J Acquir Immune Defic Syndr 2006; 41: 616-23. 